\title{
Cognitive Flexibility as the Mediator between Unemployment Anxiety and Psychological Wellbeing among University Students with Disabilities
}

\author{
Shaden Khalil Hussain Alioat \\ Associate professor of Special Education, \\ Department of Special Education, Faculty \\ of Educational Graduate Studies \\ King Abdulaziz University
}

\author{
Mogeda El Sayed Aly El Keshky \\ Professor of Clinical Psychology, \\ Department of Psychology, Faculty of Arts \\ and Humanities, King Abdulaziz University, \\ Jeddah \& Assiut University, Egypt
}

\begin{abstract}
Background: Many previous studies confirm that anxious individuals usually express lower wellbeing. Additionally, being anxious usually undermines cognitive performance and prevents development of new ways of achieving desired levels of wellbeing, by reducing cognitive flexibility. This makes cognitive flexibility a possible mediator for the negative relationship between anxiety and wellbeing.

Objectives: This study tests if cognitive flexibility serves as a mediator between anxiety and psychological wellbeing, with a special focus on the unemployment anxiety experienced by individuals with disabilities.

Methods: Research assistants collected the data from 155 Saudi individuals with different disabilities (71 men and 84 women) between February and May 2019. The data was collected by questionnaires (Unemployment Anxiety Questionnaire, Ryff's Psychological Wellbeing Scale, Cognitive Flexibility Inventory), and analyzed in $R$. After checking for and obtaining valid factor structures, path analyses were conducted to obtain the results.

Results: The applied path analyses have shown that cognitive flexibility serves as a partial mediator between unemployment anxiety and psychological wellbeing..

Conclusion: Cognitive flexibility partially mediates the relationship between unemployment anxiety and wellbeing. However, the failure to replicate the factor structures of the applied questionnaires provides both valuable insight into potential cultural differences and highlights the need to replicate the study with the use of more culturally adapted and validated measures.
\end{abstract}

Keywords: unemployment anxiety, cognitive flexibility, resilience, wellbeing, disabilities.

\section{Introduction}

Financial status affects various life domains. Everything from food choices to holiday destinations may be defined by the financial resources a person has. Meagre financial resources may undermine longterm plans and also a sense of personal wellbeing. Deci and Ryan(2000) explain that wellbeing can grow on three stable pillars: autonomy, competence and relatedness with others. Financial 
dependence directly undermines personal autonomy, and might lead to deteriorated wellbeing. Several studies show low financial capacity is an important factor in deteriorated wellbeing (MohseniCheraglou, 2016; Taylor, Jenkins and Sacker, 2011), while having a cash margin is a positive predictor of wellbeing, regardless of the source(Berlin and Kaunitz, 2015). Multiple studies agree that being financially stable (or perceiving oneself as such) is important for wellbeing, implying that financial instability may lead to deteriorated wellbeing. Being in employment is usually the main source of financial stability. There is a wide consensus in the research community that employees enjoy better levels of psychological well-being compared to the unemployed (Wood \& Burchell,2018). Analysis of non-disabled individuals has shown that even temporary unemployment can undermine personal wellbeing for long periods, men more so than women(Knabe \& Rätzel,2010). While Burchell(2011) has shown that this may last for a year, Viinamäki and colleagues(1993) explain that with higher uncertainty regarding the future and lower social support, men are more vulnerable to insecurity. Mousteri and colleagues(Mohseni-Cheraglou, 2016) considered the relation between unemployment and psychological wellbeing in 14 countries in Europe. Unemployment impact on well-being is modelled based on a linear, multi-level specifications. The researchers found that every six months of unemployment in a person's career predicts a reduction in the well-being after the age of 50. Binder and Coad(Binder \& Coad, 2015) considered the unemployment-unhappiness relationship in more detail. They found that mental wellbeing is more affected by unemployment compared to life satisfactions. When analyzing the full subjective well-being distribution, they found that individuals on the lower deciles of the well-being distribution are the most strongly affected by unemployment. Although employment provides the simplest way to financial stability, not everyone has equal chances of getting a job, especially the disabled. While non-disabled individuals see such unemployment negative episodes of uncertainty as temporary, they take up a much larger portion of time for individuals with disabilities. In that context, it is reasonable to presume that anxiety regarding finding and keeping a job is higher for disabled individuals, which indicates higher levels of stress and, consequently, lower wellbeing (Deci \& Ryan,2000). Previous studies (Turner\& Turner, 2004) suggest that the impact of unemployment on the emotional status of a disabled person is greater than an individual with no disability.

Many social groups are stigmatized because of their characteristics, some of which relate to physical health. Having to ask for help can imply one is inferiority, which may fuel stigma(Read, Morton and Ryan, 2015).These individuals have to risk their social identities in pursuit of social equality, however, society occasionally remains non-responsive and rejects changes that would reduce inequality(Waterfeld and Whelan, 2015). One such area is related to employment policies, since individuals with disabilities may be perceived as less capable than non- 
disabled individuals. Although policies promoting employment of these individuals exist(e.g., Frank, 2016) and steps have taken towards their complete inclusion in society, individuals with more severe disabilities may still have difficulty entering the work world. Bell and Mino(2013)have shown that the unemployment rate among US citizens with vision loss is consistently about $37 \%$, but Grussenmeyer and colleagues(2017)argue it should really be about $70 \%$. Similarly, unemployment of individuals with hearing impairment in the USA is approximately $52 \%$, which is much larger than the unemployment rate for nondisabled individuals(Garbergolio, Cawthon and Bond, 2016). While people with disabilities are aware of the social norm of work(Stam et al., 2016),they are also aware of society's attitudes towards those who do not work. Although studies have indicated that managers who are more knowledgeable about vision loss are more likely to hire a person with that disability, most managers are not very knowledgeable about it and tend to think that those individuals are less effective than nondisabled workers, less versatile than they actually are, and expensive to employ(Lynch, 2013; McDonnall, O’Mally and Crudden, 2014).

Many studies have shown there are individual differences in how well people deal with anxiety. A new key term in this field - resilience - denotes an individual's tendency to successfully cope with stress, recover from unfavorable circumstances and move on with life(Smith et al., 2008).Resilience is seen as the protective factor against threats to wellbeing, so ways to operationalize it have developed(Bartone, 2007; Connor and Davidson, 2003; Oshio et al., 2003; Smith et al., 2008; Wagnild, and Young, 1993). Although these scales theoretically measure the same construct, their correlations are usually moderate to high, (Madewell and Ponce-Garcia, 2016; Rodriguez-Rey, Alonso-Tapia and Hernansaiz-Garrido, 2016)indicating that some measures tap into different variances than others. This may possibly lie in the concept's structure, as resilience might have different sources. For instance, while some individuals may rely on social support in critical times, others may use their own resources more creatively. The concept describing this personal ability is flexibility. Some researchers focus on its cognitive aspects by defining it as cognitive flexibility (i.e., the ability to switch attention when doing multiple cognitive tasks), and reveal that even this form represents a protective factor against threats to wellbeing(Mobbs et al., 2011; Quota, El-Sarraj and Punamaki, 2001).Others focus more on its creative factors by defining it as the ability to recognize and adapt to situational demands, shift mindset or behavioral repertoire, maintain balance among relevant domains of life and exhibit behaviors congruent with values in private and organizational contexts (Bond, Hayes and Barnes-Holmes, 2006). While Kashdan and Rottenberg (2010) explain that this kind of flexibility is missing in many mental health disorders, Bond and colleagues(2006) conclude that use of Acceptance and Commitment Therapy (ACT) focused on cognitive flexibility 
improvements relates to enhanced organizational behavior and health, which has been confirmed by another randomized control trial study(Fledderus et al., 2009). Taken together, these studies convey a unique idea - that cognitively flexible individuals have more resilient mental health.

If cognitive flexibility deals with different mental health issues so effectively, would it also be effective in dealing with the anxiety and stigma that disabled people face when thinking about their future? One study, based on a sample of healthy undergraduate college students, shows that cognitive flexibility is moderately negatively related to depression, somatization and anxiety, accounting for $15-20 \%$ of the variance of anxiety(Masuda and Tully, 2011). Another study, conducted on a clinical sample, confirmed that Dialectical Behavior Therapy (DBT) focused on the development of cognitive flexibility reduces the extent of anxious symptoms in patients(Webb et al., 2017). Probably the most relevant confirmation of cognitive flexibility's role (relating to unemployment of individuals with disabilities) comes from cancer survivors living in constant fear of their cancer's recurrence. Arch and Mitchell applied Acceptance and Commitment Therapy (ACT) to a group of 42 such individuals, which led to a moderate reduction of their depressive and anxious symptoms(Arch \& Mitchell ,2015). These studies indicate that higher cognitive flexibility relates to lower anxiety, that strengthened flexibility weakens anxiety, even when the threat cannot be completely eliminated.
Considered together, these studies suggest that higher cognitive flexibility may be a source of resilience for individuals with disabilities anxious about future employment. In the Saudi context, no previous work has considered the relation between cognitive flexibility, unemployment anxiety and psychological well-being among Saudi disabled individuals. The scarcity of such studies, especially in the Saudi context, motivated us to conduct this study. It will also focus on the roles of disability and gender in the relationships between cognitive flexibility, anxiety about future unemployment and psychological wellbeing. For instance, do disabled individuals face different obstacles when seeking employment? Recent studies suggest that employment needs of the disabled people are not adequately perceived by the labour market, and they tend to be excluded from the recruitment process, reducing their employment opportunity(Mirjana,2016; Piggott, Sapey and Wilenius, 2005; Crawford, 2000). Additionally, some studies highlight the role of gender in the process of employing a disabled person These studies conclude that impaired men in the USA are more likely to find a job compared to impaired women, but not in Denmark (Bell \& Mino, 2013; Dammeyer, Crowe, Marschark and Rosica, 2019). Therefore, It is relevant to study both the role of gender and the disability in the interplay between mental health and employment for individuals with disabilities. Although the authors of this current study failed to find any empirical testing of this complex relationship, this 
issue also served as motivation for conducting this study.

\section{Research questions}

The main goal of this study is to assess if the relationship between anxiety regarding unemployment and psychological wellbeing is mediated by cognitive flexibility. This study will then focus on the potential roles of gender and disability type as moderators of that relationship, by focusing on the differences in the average levels of unemployment anxiety.

\section{Methods}

\section{Participants}

This study's proposed sample comprised 157 students with disabilities from Saudi universities, who volunteered to join the study. Two of them were excluded from the analysis for providing incomplete answers, so the analyses conducted in this study were based on the 155 participants, who remained to the study's conclusion. There were 71 men and 84 women, averaging 21.18 years old $(S D=2.49$ ), with one participant inputting an invalid age. All participants had a disability: visual $(n=70)$, hearing $(n=21)$, mobility $(n=$ 46). Only a few had a chronic disease $(n=$ $14)$, or learning disability $(n=4)$, which imposed some limitations on the applied analyses.

\section{Instruments}

The Unemployment Anxiety Questionnaire : was formed by the researchers for this study. It comprises 25 statements about various stress-related aspects of future unemployment. Participants expressed their level of agreement with each statement on a five-level Likert-type scale. The principal component analysis conducted on this scale yielded a tri-factor solution with weakly correlated factors: anxiety regarding the future, anxiety regarding potential and anxiety regarding self-confidence. These principal components are shown in Appendix A. These scores were saved in regression format for each participant and used in the later analyses.

Ryff's Psychological Wellbeing Scale : (Ryff, 1989; Ryff et al., 2007)translated into Arabic by Mogeda ElKeshky was used to measure the psychological wellbeing of participants. It comprises 42 items to which participants state their level of agreement on a six-level Likert-type scale. Theoretically, this scale consists of six correlated dimensions of wellbeing - selfacceptance, positive relationships with others, autonomy, environmental mastery, purpose in life and personal growth(Ryff, 1989; Ryff and Keyes, 1995). Ryff and Keyes(1995) also reveal that a single higher-order factor structure with six firstorder factors also fits the data well, with a higher score indicating higher psychological wellbeing. The Confirmatory Factor Analysis (CFA) with a robust maximum likelihood estimator conducted on the obtained data failed to confirm this factor structure $(\chi 2(804)=$ $3853.99, p<0.001$, robust $\mathrm{CFI}=0.48$, robust RMSEA $=0.15$ ), thus implying the need to form new, culturally appropriate factors. The PCA with MAP test conducted on the data collected by this study indicated that the optimal number of components would be seven, although such a solution yielded ultra-Heywood cases with communalities over 1 . These factor scores were used as data for another PCA which yielded a single factor of 
psychological wellbeing (see Appendices $\mathrm{B}$ and $\mathrm{C}$ ).

The Cognitive Flexibility Inventory (CFI20): was used to operationalize cognitive flexibility of the participants. Its scale comprises 20 items regarding the handling of difficult situations, that participants estimate their level of agreement with. In its original version, the scale consisted of two moderately correlated factors, the first factor representing availability of alternatives and the second factor representing the control over situation. However, a validation study conducted among Iranian students reveals a threefactor structure with highly correlated factors(Shareh, Farmani and Soltani, 2014). The confirmatory factor analysis with maximum likelihood estimator robust on non-normality of the data distribution conducted on this sample also revealed that the theoretical structure of the questionnaire does not fit the data $(\chi 2(169)$ $=674.30, p<0.001$, robust $\mathrm{CFI}=0.78$, robust RMSEA $=0.13$ ), indicating that a better solution should be found. The principal component analysis with the MAP test as the criterion for the optimal number of factors conducted on the results of this study also yielded a three-factor structure, although many of the items were cross-loaded and the correlations between factors were high. Therefore, in line with the outcomes of previous studies(Dennis and Vander Wal, 2010; Shareh et al., 2014) and the intention of using the best practices available, another PCA was conducted on the extracted scores in order to extract a second-order factor - cognitive flexibility. These principal components are shown in Appendixes D and E. In this study, since component axes were rotated (using rotation method promax with Kaiser normalization) so that higher scores indicate less flexibility, the higher component scores also indicate less psychologically flexible individuals.

\section{Procedure}

The data were collected in person by trained individuals $(n=10)$, with each participant individually filling the questionnaires with help from a trained research assistant. Where possible, participants filled the questionnaires themselves and the assistant stood by passively, however when participants were unable to solve the questionnaire themselves (e.g., participants with visual impairment), assistants marked their answers on the paper. The data were collected from February to May 2019.

After the introductory questionnaire about basic socio-demographic data and impairment type, the second questionnaire (psychological wellbeing) was presented, followed by the third one (unemployment anxiety and cognitive flexibility). The order of presenting the questionnaires to participants was constant. They were reminded of the issues before they responded about how they faced them. Within a questionnaire the order of the items was randomized across participants. It was decided to present the psychological wellbeing questionnaire first, before being exposed to the unemployment issue, so that the participant's wellbeing-related responses are not momentarily affected by unemployment worries. Participants were not rewarded for taking a part in this study. The study was designed to meet all the required standards of ethical procedures for 
testing, as it is the prime responsibility of a researcher to fulfil theses ethical requirements, including confidentiality, anonymity and autonomy. ${ }^{45}$ The participants were informed about the relevance of the research being conducted, and both written and verbal consent were taken prior to recording their responses. All participants were informed about their right to withdraw from the study at any moment.

The structural equation modelling (SEM) was done in three steps. Firstly, the general SEM was conducted on the entire sample, followed by two multi-group SEMs with gender and disability type as grouping variables.

\section{Statistical analysis :}

$R$ was used for statistical analyses in this study. The packages lavaan (Rosseel, 2012), semTools (Jorgensen et al., 2018),

Table 1: Pearson's correlation coefficient between anxiety, gender, cognitive flexibility and wellbeing

(1)

(2)

$0.27^{*}$

0.13

(4)

1

0.13

$-0.72^{* *}$

(5)

(6)

(2) Anxiety regarding self-confidence

(3) Anxiety regarding future

1

(4) Psychological wellbeing

(5) Cognitive inflexibility

(6) Gender

The table of correlations (Table 1) shows the correlations between anxiety, gender, cognitive flexibility and wellbeing in our sample of 155 Saudi students after applying Bonferroni's correction of significance. It shows that all the anxiety variables are significantly and negatively correlated to psychological wellbeing, indicating that more anxious participants also exhibited lower wellbeing. Less Cognitive flexibility is negatively related to psychological wellbeing, indicating that less flexible individuals on average expressed lower levels of psychological wellbeing. A positive relationship between anxiety and less cognitive flexibility has been found, indicating that individuals more anxious about their future and potential are on average less cognitively flexible than those who are less anxious. This was not found with respect to 
self-confidence, indicating that uncertainty in oneself is not related to cognitive flexibility. The table suggests that the role of gender in this context is nonsignificant.

Next, path analysis was conducted on the extracted factor scores. In order to obtain results robust to deviations from the normal distribution (Figure 1), a robust version of the maximum likelihood estimator was applied in the upcoming structural equation modeling(Strang et al., 2017).

Figure 1 : Distributions of unemployment anxiety, psychological wellbeing and cognitive flexibility
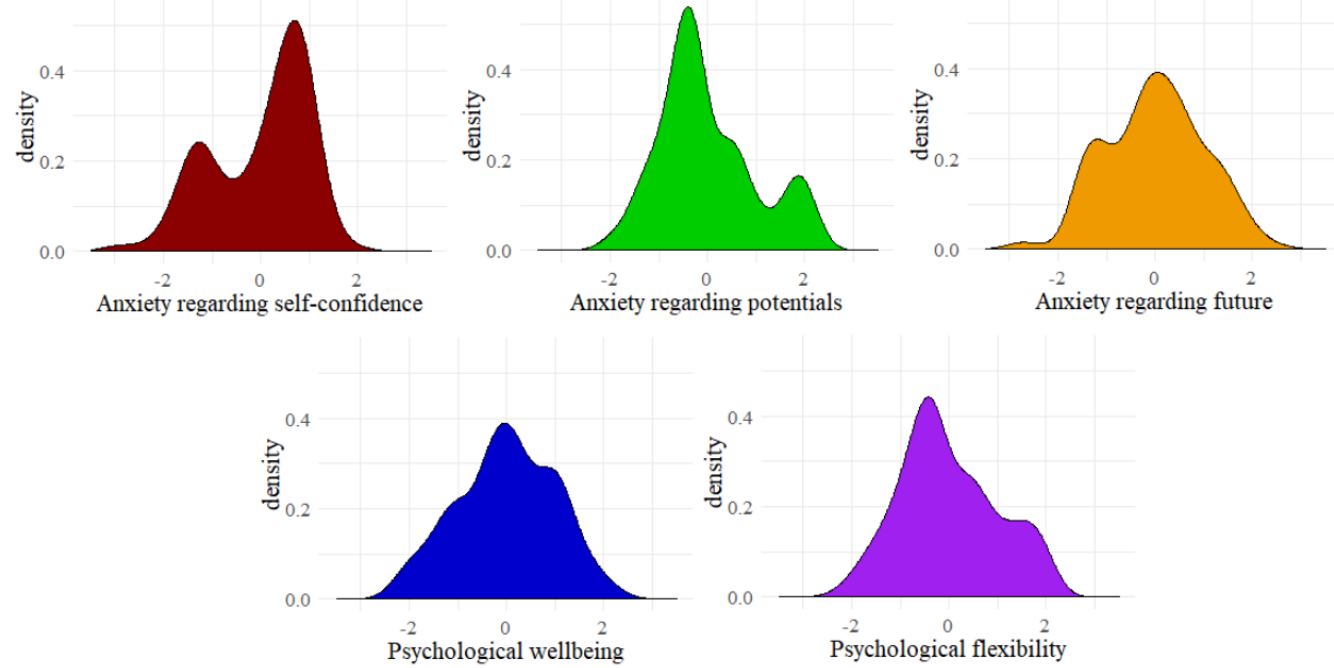

Figure 2: Cognitive flexibility as the mediator (and suppressor) between unemployment anxiety and psychological wellbeing - standardized coefficients

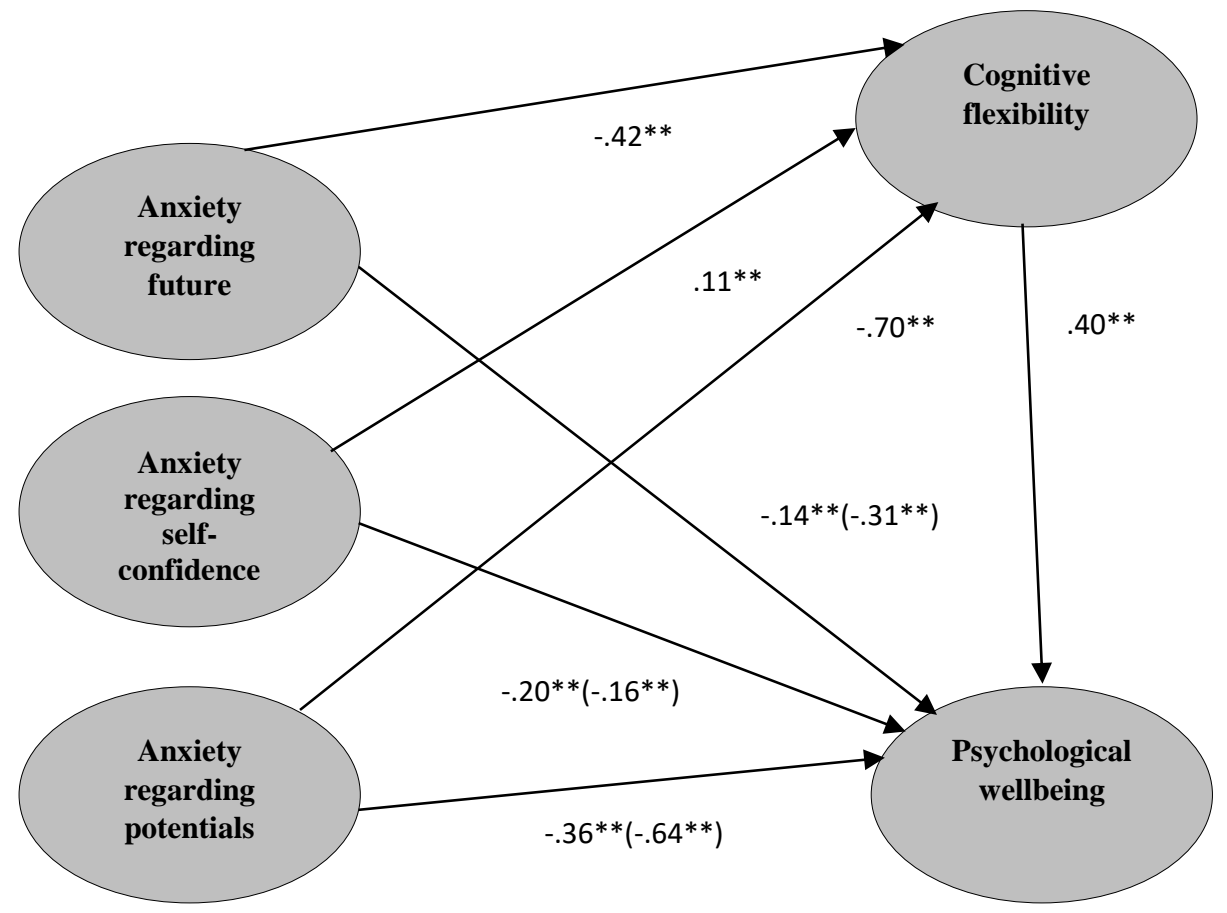


The structural model presented in Figure 1 shows multiple relevant findings. Anxiety, regardless of its type, is shown as the negative predictor of wellbeing, which confirms the previously discussed findings in Table 1 and indicates that different types of anxiety relating to future employment have unique contributions to the prediction of psychological wellbeing. Psychological wellbeing is also predicted by less cognitive flexibility, with less flexible individuals having lower psychological wellbeing. In sum, these four predictors account for the majority of variance in psychological wellbeing $\left(R^{2}=0.694\right)$. While participants with lower anxiety regarding self-confidence are found to be more flexible, individuals with high anxiety regarding their future and especially those with high anxiety regarding their potential are on average less psychologically flexible. This accounts for almost $70 \%$ of variance of cognitive flexibility $\left(R^{2}=0.691\right)$. In the context of mediations, less cognitive flexibility is not shown as the complete mediator of unemployment anxiety being the predictor of psychological wellbeing. However, cognitive flexibility is shown to be the suppressor of the relationship between anxiety regarding self-confidence and psychological wellbeing $(b=0.044, p=$ $0.006)$ and to be a partial mediator between anxiety regarding potential $(b=-0.276, p<$ $0.001)$ and anxiety regarding the future $(b$ $=-0.166, p<0.001)$ being predictors of psychological wellbeing. Therefore, a significant portion of the relationship between the latter two types of anxiety and psychological wellbeing can be attributed to less cognitive flexibility.

In order to conduct the multi-group analysis, pairs of models were formed: in the first model, regression coefficients were unconstrained; in the second model the appropriate pairs of regression coefficients were constrained to be equal. However, results of the applied $\chi^{2}$ test revealed that gender $\left(\chi^{2}(7)=11.64, p=\right.$ $0.113)$ and type of disability $\left(\chi^{2}(14)=\right.$ $16.39, p=0.290$ ) were not moderators of any of the relationships discussed just previously. Differences with respect to mean scores of these constructs were also tested in a similar fashion. Although this testing revealed some differences between male and female students with disabilities with respect to means of unemployment anxiety, cognitive flexibility and psychological wellbeing $\left(\chi^{2}(5)=17.92, p=\right.$ $0.003)$, none of the modification indices reached the threshold of significance $\left(\chi^{2}(1)\right.$ $=3.84$ ), indicating that although there are some differences in means on the level of the entire model, none of them can with reasonable certainty be declared meaningful. Students with different disabilities did not differ either, with respect to means of the explored constructs $\left(\chi^{2}(10)=16.16, p=0.095\right)$.

\section{Discussion}

Our findings confirm some of the results obtained in earlier studies. In line with them(Burchell, 2011; Knabe and Ratzel, 2010; Viinamaki et al., 1993) higher unemployment anxiety predicts lower wellbeing for both men and women. Unlike those studies though, these results indicate no gender difference, which could 
reflect something specific to the culture. Earlier studies show that in some, but not all cultures, men with disabilities are more likely to find a job than women with disabilities(Bell and Mino, 2013; Dammeyer et al., 2019). However, an important distinction between objective and perceived unemployment threat should be made, as subjective estimates, not objective numbers, determine behavior. Although men with disabilities might be slightly better off than women with disabilities, the relationship between unemployment worry and psychological wellbeing is similar.

Less cognitive flexibility, also in line with previous studies(Masuda and Tully, 2011; Webb et al., 2017)has been shown to be the predictor of poorer psychological wellbeing. Less flexible individuals exhibit lower psychological wellbeing for both men and women with disabilities. Flexibility is predicted by all three unemployment anxiety components, although anxiety regarding potential was the strongest predictor of mental inflexibility. This especially strong relationship could be explained by their similarity of content - both constructs rely on having multiple acceptable options for use in critical situations. However, since the factor structures of this study's data did not perfectly match those presented originally, further studies are required to assess the construct validity of these conclusions. With regard to the selfconfidence component of anxiety, the results show a different type of relationship to cognitive flexibility compared to anxiety regarding future and potential. Participants with higher self-confidence showed higher cognitive flexibility. This result is consistent with a study(Malkoc \& Multu ,2019) on Turkish students that showed a similar relationship between anxiety regarding self-confidence and cognitive flexibility.

The most interesting results confirm the role of cognitive flexibility as the partial mediator between unemployment anxiety and psychological wellbeing. The result is in line with studies using DBT and ACT treatments that assumes that less cognitive flexibility contributes negatively to anxiety(Webb et al., 2017; Arch \& Mitchell,2016). However, the results of this study indicates a relationship in the other direction, with unemployment anxiety leading to less cognitive flexibility. More research work is needed to explore more the dynamics of such directional relationship. This generally confirms the notion that having multiple options reduces the stress related to an uncertain future and expected opportunities. However, although it reduces stress, it does not remove it, as anxiety remains a significant predictor of psychological wellbeing even after flexibility has been controlled for. This finding indicates that although a flexible mindset can serve as a protective factor to a certain extent, some unemployment anxiety will remain despite interventions focused on improving it. Although a more flexible mindset is better at dealing with the unpleasantness of living with disabilities, mental flexibility cannot completely replace the missing resource.

This study also tested the role of gender and disability type as moderators of the previously described relationships, in terms of the model's intercepts and regression 
slopes. The results fail to support this, as the number of participants with specific limitations (e.g., auditory disabilities) was too low to obtain stable regression coefficients. This led to combining multiple groups of disabilities in order to reach adequate group sizes, which might have undermined the effectiveness of the applied tests. Therefore, although this study fails to confirm the existence of differences in the anxiety-wellbeing relationship with respect to disability type, it cannot be ruled out and requires further study.

Taken together, these findings highlight several important characteristics of unemployment anxiety for individuals with disabilities, which could be used to further enhance society so every individual can develop his or her skills and contribute meaningfully. Earlier studies(Frank, 2016) noted that individuals with disabilities have been successfully included in society, although the stigmatizing attitudes among non-disabled managers and people towards individuals with disabilities may still exist(Lynch, 2013; McDonnall, O'Mally and Crudden, 2014). Awareness of this might be why cognitive flexibility does not completely mediate the relationship between unemployment anxiety and psychological wellbeing. Such awareness may trigger self-fulfilling prophecies: managers may have lower expectations of those workers and allow them less opportunity to show their skills for employment or promotion; individuals with disabilities may be more discouraged at the outset and by unjust opportunities, which then leads to worry, disengagement and deteriorated wellbeing. In order to counter-act this effect, it is crucial to focus efforts on both disabled employees and employers. Individuals with disabilities could benefit from consultations making them aware of their hidden options, and teaching them how to present their capabilities so future employers can see their potential. Employers could benefit from greater awareness on how to discover and exploit the potential and skills of employees with disabilities, given their special characteristics and the profile of their disability. Such an approach might be even more effective than simple interventions, which are provided only to those individuals brave enough to ask for help.

\section{Limitations}

Several limitations of this study should also be considered while interpreting its results. This study was conducted as a correlational study, which disallows the formation of firm causal conclusions. Although psychometrically validated instruments were used to operationalize relevant constructs, their factor structure was not confirmed. Multiple potential reasons exist for such conclusions, one being the use of instruments formed in Western cultures on a sample from a different cultural background; another being the use of instruments validated on non-disabled participants for a sample with different disabilities. Future studies should include multiple operationalizations of these constructs to ascertain their construct validity. Given the Saudi context of the research, culture-specific factors, particularly, religion beliefs can be considered in a future study. Zmigrod and colleagues(2018)investigated the relation 
between cognitive flexibility and religious adherence, practice and rituals. Their findings show that religious practicing can be linked to less cognitive flexibility and more persistence. In another study, Alshowkan and colleagues(2015)investigated the factors affecting the quality of life of Saudi individuals suffering from schizophrenia. The study results indicate the positive role of religious practice in improving the quality of life of schizophrenia Saudi sufferers. It would be of interest to study how the major influence religion has in the Saudi society could affect the role of cognitive flexibility as a mediator between unemployment anxiety and well-being among the Saudis with disabilities. Another potential limitation concerns the choice of participants, as the sampling was not random. University students are not a bad choice for studying participants in this context, as they invest lots of time and effort into activities that should improve their odds of finding a job, although that cannot be guaranteed. However, the very fact that they made it all the way through to their tertiary education may reflect the fact that their resources are less affected by their disabilities, because of better genetics or more training to date, than for others with more complex or multiple disabilities. Higher intelligence, which is correlated with cognitive flexibility(e.g., Strang et al., 2017)might have made this population sample more effective than the rest of the population of individuals with disabilities. That makes it relevant to extend the research process to include such participants. Due to limited financial resources for training assistants, the inclusion of such extra respondents was not feasible. However, in future studies it would be interesting to include some measure of functionality, as more severe disabilities may cause more unemployment anxiety. It would be interesting to include other relevant constructs like the perception of the norm of work(Stam et al., 2016)or of self-stigmatization based on what people without disabilities think, as these might also affect an individual's anxiety when confronted with the competitive work world. Inclusion of unemployed participants without disabilities as a control group could reveal to what extent individuals with disabilities are more anxious, than those without, regarding employment.

\section{Conclusion}

This study reveals that individuals with disabilities who experience unemployment anxiety also exhibit lower levels of psychological wellbeing, which is partially mediated by cognitive inflexibility. Differences in unemployment anxiety with respect to gender and disability were observed. As a result, the study confirms previous findings that application of interventions based on increasing cognitive flexibility may indeed lower unemployment anxiety, and thus lead to improvements in the psychological wellbeing of individuals with disabilities.

\section{Acknowledgments}

This project was funded by the Deanship of Scientific Research (DSR), at King Abdulaziz University, Jeddah, under grant no. (M-10-279-40). The authors, therefore, acknowledge with thanks to DSR for their technical and financial support. 


\section{References}

Alshowkan, A., Curtis, J. \& White, Y. (2015). Factors affecting the quality of life for people with schizophrenia in Saudi Arabia: a qualitative study. Journal of Psychiatry, 18, 4.

Arch, J. J., \& Mitchell, J. L. (2016). An Acceptance and Commitment Therapy (ACT) group intervention for cancer survivors experiencing anxiety at re-entry. Psycho-Oncology, 25(5), 610-615. Available at:

- $\quad$ http://thehappinesstrap.com/wpcontent/uploads/2017/06/Arch-_-

Mitchell-2015-ACT-for-anxiety-insurvivors-of-cancer.pdf

Bartone, P. T. (2007). Test-retest reliability of the dispositional resilience scale15 , a brief hardiness scale. Psychological reports, 101(3), 943944. Available at: https://journals.sagepub.com/doi/abs/ 10.2466/pr0.101.3.943-944

Bell, E. C., \& Mino, N. M. (2013). Blind and visually impaired adult rehabilitation and employment survey: Final results. Journal of Blindness Innovation \& Research,3(1),1-35.Available at:

http://yourtechvision.com/2013/04/04 /blind-and-visually-impaired-adultrehabilitation-and-employmentsurveyfinal-results/

Berlin, M., \& Kaunitz, N. (2015). Beyond income: The importance for life satisfaction of having access to a cash margin. Journal of Happiness Studies, 16(6),1557-1573.Available at: https://link.springer.com/article/10.10 07/s10902-014-9575-7

Binder, M., \& Coad, A. (2015). Heterogeneity in the Relationship Between Unemployment and Subjective Wellbeing: A Quantile Approach. Economica, 82, 865-891.

Bond, F. W., Hayes, S. C., \& BarnesHolmes, D. (2006). Cognitive flexibility, ACT, and organizational behavior. Journal of Organizational Behavior Management,26(1-2),2554.Available at:

https://www.tandfonline.com/doi/pdf/ 10.1300/J075v26n01_02?casa_token =qo0rgKEC7MMAAAAA:DtPOcEE zjunuhK3v8ZBQswLtOiJRx08jrj9gB iw1aDsemDJQrhtWsN90I9WocuMg92ajMSSe5gxl2E

Burchell, B. (2011). A temporal comparison of the effects of unemployment and job insecurity on wellbeing. Sociological Research Online, 16(1), 1-13. Available at: http://www.socresonline.org.uk/16/1/ 9.html.bak

Connor, K. M., \& Davidson, J. R. (2003). Development of a new resilience scale: The Connor-Davidson resilience scale (CD-RISC). Depression and anxiety, 18(2),76-82. Available at:

https://onlinelibrary.wiley.com/doi/pd f/10.1002/da. 10113

Crawford, C., \& Martin, T. (2000). Job accommodations and other employment measures in Canada: An examination of employer practices and costs concerning employees with disabilities. Toronto: Roeher Institute. 
Dammeyer, J., Crowe, K., Marschark, M., \& Rosica, M. (2019). Work and Employment Characteristics of Deaf and Hard-of-Hearing Adults. The Journal of Deaf Studies and Deaf Education. Available at: https://academic.oup.com/jdsde/adva ncearticle/doi/10.1093/deafed/enz018/54 86450?casa_token $=$ OmSVnE3PIeIA AAAA:aSGAokk1pfddvKKoW7tEQ 0QfZVBb7j6RIg8nhGPtDguEHe7kL qCgelVhbTSItX1tlD5HZsGhrh6e

Deci, E. L., \& Ryan, R. M. (2000). The" what" and" why" of goal pursuits: Human needs and the selfdetermination of behavior. Psychological inquiry, 11(4), 227268. Available at: https://www.jstor.org/stable/pdf/1449 618.pdf

Dennis, J. P., \& Vander Wal, J. S. (2010). The cognitive flexibility inventory: Instrument development and estimates of reliability and validity. Cognitive therapy and research,34(3), 241-253. Available at:

https://link.springer.com/content/pdf/ 10.1007/s10608-009-9276-4.pdf

Fledderus, M., Bohlmeijer, E. T., Smit, F., \& Westerhof, G. J. (2010). Mental health promotion as a new goal in public mental health care: A randomized controlled trial of an intervention enhancing cognitive flexibility. American journal of public health, 100(12), 2372-2372. Available at: https://ajph.aphapublications.org/doi/
full/10.2105/AJPH.2010.196196?jour $\underline{\text { nalCode }=\text { ajph }}$

Flick, U. (2015). Introducing research methodology: A beginner's guide to doing a research project. Sage.

Frank, A. (2016, September). Vocational rehabilitation: Supporting ill or disabled individuals in (to) work: A UK perspective. In Healthcare (Vol. 4, No. 3, p. 46). Multidisciplinary Digital Publishing Institute. Available at: $\quad$ https://www.mdpi.com/22279032/4/3/46/pdf

Garberoglio, C. L., Cawthon, S., \& Bond, M. (2016). Deaf people and employment in the United States: 2016. Washington, DC: US Department of Education, Office of Special Education Programs, National Deaf Center on Postsecondary Outcomes. Available at:

https://www.nationaldeafcenter.org/si tes/default/files/Deaf\%20Employmen t\%20Report_final.pdf

Grussenmeyer, W., Garcia, J., Folmer, E., \& Jiang, F. (2017, April). Evaluating the Accessibility of the Job Search and Interview Process for People who are Blind and Visually Impaired. In Proceedings of the 14th Web for All Conference on The Future of Accessible Work (p. 3). ACM. Available at: https://www.researchgate.net/profile/ Eelke Folmer/publication/317989185 Evvaluating_the_Accessibility_of_th e Job_Search and Interview_Proces s for People who are Blind and V isually_Impaired/links/59f7e7f6a6fdc c075ec7c618/Evaluating-the- 
Accessibility-of-the-Job-Search-andInterview-Process-for-People-whoare-Blind-and-Visually-Impaired.pdf Harrel, F. E. (2019). Package 'Hmisc'. Retrieved from: https://cran.rproject.org/web/packages/Hmisc/Hmi sc.pdf

Jorgensen, T. D., Pornprasertmanit, S., Schoemann, A. M., \& Rosseel, Y. (2018). semTools: Useful tools for structural equation modeling. Retrieved from: https://CRAN.Rproject.org/package $=$ semTools

Kashdan, T. B., \& Rottenberg, J. (2010). Cognitive flexibility as a fundamental aspect of health. Clinical psychology review, 30(7), 865-878. Available at: https://www.ncbi.nlm.nih.gov/pmc/ar ticles/PMC2998793/

Knabe, A., \& Rätzel, S. (2010). Better an insecure job than no job at all? Unemployment, job insecurity and subjective wellbeing. Economics Bulletin, 30(3),2486-2494. Available at:

http://www.accessecon.com/Pubs/EB /2010/Volume30/EB-10-V30-I3P228.pdf

Lynch, K. A. (2013). Survey reveals myths and misconceptions abundant among hiring managers about the capabilities of people who are visually impaired. Journal of Visual Impairment \& Blindness, 107(6), 408-410. Available at: https://search.proquest.com/openview 15b08b78b6ce62669970dc3f94d6899 0f/1?pqorigsite $=$ gscholar $\& \mathrm{cbl}=2027465$

Madewell, A. N., \& Ponce-Garcia, E. (2016). Assessing resilience in emerging adulthood: The resilience scale (RS), Connor-Davidson resilience scale (CD-RISC), and scale of protective factors (SPF). Personality and Individual differences, 97, 249-255. Available at:

https://www.sciencedirect.com/scienc e/article/abs/pii/S0191886916301817 Malkoc, A. and Multu A. K. (2019). Mediating the Effect of Cognitive Flexibility in the Relationship between Psychological Well-Being and Self-Confidence: A Study on Turkish University Students. International Journal of Higher Education. 8, 278-287.

Masuda, A., \& Tully, E. C. (2012). The role of mindfulness and cognitive flexibility in somatization, depression, anxiety, and general psychological distress in a nonclinical college sample. Journal of EvidenceBased Complementary \& Alternative Medicine, 17(1), 66-71. Available at:

https://journals.sagepub.com/doi/pdf/ $\underline{10.1177 / 2156587211423400}$

McDonnall, M. C., O'Mally, J., \& Crudden, A. (2014). Employer knowledge of and attitudes toward employees who are blind or visually impaired. Journal of Visual Impairment \& Blindness, 108(3), 213-225. Available at:

https://search.proquest.com/docview/ 1534733525?pq-origsite $=$ gscholar

Mirjana, R. M. (2016). Empowering Employment of Women and Marginalized People Through 
Entrepreneurship Education in Serbia. Journal of Women's Entrepreneurship and Education, 1-2, 3-17.

Mobbs, O., Iglesias, K., Golay, A., \& Van der Linden, M. (2011). Cognitive deficits in obese persons with and without binge eating disorder. Investigation using a mental flexibility task. Appetite, 57(1), 263271. Available at: http://doc.rero.ch/record/259570/files Iglesias_Katia_-

Cognitive deficits and attentional biases for food and 20160511.pdf

Mohseni-Cheraghlou, A. (2016). The aftermath of financial crises: a look on human and social wellbeing. World Development, 87, 88-106. Available at: https://www.sciencedirect.com/scienc e/article/abs/pii/S0305750X16303965

Qouta, S., El-Sarraj, E., \& Punamäki, R. L. (2001). Mental flexibility as resiliency factor among children exposed to political violence. International Journal of Psychology, 36(1), 1-7. Available at:

https://www.tandfonline.com/doi/abs/ $\underline{10.1080 / 00207590042000010}$

Oshio, A., Kaneko, H., Nagamine, S., \& Nakaya, M. (2003). Construct validity of the adolescent resilience scale. Psychological reports, 93(3_suppl), 1217-1222. Available at:

https://www.researchgate.net/profile/ Atsushi_Oshio/publication/8883287 Construct_validity_of_the_Adolescen t Resilience Scale/links/0912f50fdcf 0e8e4b9000000.pdf

Piggott, L., Sapey, B., \& Wilenius, F. (2005). Out of touch: local government and disabled people's employment needs, Disability \& Society, 20, 599-611.

Read, S. A., Morton, T. A., \& Ryan, M. K. (2015). Negotiating identity: a qualitative analysis of stigma and support seeking for individuals with cerebral palsy. Disability and rehabilitation, 37(13), 1162-1169. Available at: http://researchspace.bathspa.ac.uk/11 519/1/11519.pdf

Revelle, W. (2018) psych: Procedures for Personality and Psychological Research. Retrieved from: https://CRAN.Rproject.org/package=psych

Rodríguez-Rey, R., Alonso-Tapia, J., \& Hernansaiz-Garrido, H. (2016). Reliability and validity of the Brief Resilience Scale (BRS) Spanish Version. Psychological assessment, 28(5), e101. Available at:

https://www.researchgate.net/profile/ Helena_Garrido-

Hernansaiz/publication/277953219_R eliability_and_Validity_of_the_Brief Resilience Scale BRS Spanish Ve rsion/links/580e452808ae51b863966 c7c.pdf

Rosseel, Y. (2012). lavaan: An R Package for Structural Equation Modeling. Journal of Statistical Software, 48(2), 1-36. URL

http://www.jstatsoft.org/v48/i02/ 
Ryff, C. D. (1989). Happiness is everything, or is it? Explorations on the meaning of psychological wellbeing. Journal of personality and social psychology, 57(6), 1069-1081. Available

at:

https://www.researchgate.net/profile/ Espen_Roysamb/post/Can_anybody suggest_references_regarding_Ryffs _ psychological_well-

being model/attachment/59d63616c4 9f478072ea3db0/AS:2736440124088 32@1442253224136/download/Ryff $+1989 . \mathrm{pdf}$

Ryff, C. D., \& Keyes, C. L. M. (1995). The structure of psychological well-being revisited. Journal of personality and social psychology, 69(4), 719-727. Available at: http://www.aging.wisc.edu/midus/fin dings/pdfs/830.pdf

Ryff, C. D., Almeida, D. M., Ayanian, J. S., Carr, D. S., Cleary, P. D., Coe, C., ... Williams, D. (2007). National Survey of Midlife Development in the United States (MIDUS II), 20042006: Documentation of the Psychosocial Constructs and Composite Variables in MIDUS II Project 1. Ann Arbor, MI: Interuniversity Consortium for Political and Social Research.

Shareh, H., Farmani, A., \& Soltani, E. (2014). Investigating the reliability and validity of the cognitive flexibility inventory (CFI-I) among Iranian university students. Practice in clinical psychology, 2(1), 43-50. Available at: http://jpcp.uswr.ac.ir/files/site1/user_f iles 261192/farmani-A-10-118-2807ae10.pdf

Smith, B. W., Dalen, J., Wiggins, K., Tooley, E., Christopher, P., \& Bernard, J. (2008). The brief resilience scale: assessing the ability to bounce back. International journal of behavioral medicine, 15(3), 194200. Available at: https://link.springer.com/content/pdf/ 10.1080/10705500802222972.pdf

Stam, K., Sieben, I., Verbakel, E., \& de Graaf, P. M. (2016). Employment status and subjective well-being: the role of the social norm to work. Work, employment and society, 30(2), 309-333. Available at:

http://citeseerx.ist.psu.edu/viewdoc/d ownload?doi=10.1.1.905.6476\&rep=r ep1\&type $=p d f$

Strang, J. F., Anthony, L. G., Yerys, B. E., Hardy, K. K., Wallace, G. L., Armour, A. C., ... \& Kenworthy, L. (2017). The Flexibility Scale: development and preliminary validation of a cognitive flexibility measure in children with autism spectrum disorders. Journal of autism and developmental disorders, 47(8), 2502-2518. Available at:

https://www.researchgate.net/publicat ion/317038573_The_Flexibility_Scal e Development and Preliminary Va lidation of a Cognitive Flexibility Measure_in_Children_with_Autism_ Spectrum Disorders

Taylor, M., Jenkins, S., \& Sacker, A. (2011). Financial capability, income and psychological wellbeing (No. 
2011-18). ISER Working paper series. Available at: https://www.econstor.eu/bitstream/10 $\underline{419 / 65970 / 1 / 667475834 . p d f}$

Turner, J. B., \& Turner, R. J. (2004). Physical Disability, Unemployment, and Mental Health. Rehabilitation Psychology, 49, 241-249.

Viinamäki, H., Koskela, K., Niskanen, L., Arnkill, R., \& Tikkanen, J. (1993). Unemployment and mental wellbeing: a factory closure study in Finland. Acta Psychiatrica Scandinavica, $88(6), \quad 429-433$. Available at:

https://onlinelibrary.wiley.com/doi/ab $\mathrm{s} / 10.1111 / \mathrm{j} .1600-$ 0447.1993.tb03486.x

Wagnild, G. M., \& Young, H. M. (1993). Development and psychometric evaluation of the Resilience Scale. Journal of Nursing Measurement, 1(2), 165-178. Available at: https://cyberleninka.org/article/n/255 719.pdf

Waterfield, B., \& Whelan, E. (2017). Learning disabled students and access to accommodations: Socioeconomic status, capital, and stigma. Disability
\& Society, 32(7), 986-1006. Available at: https://www.tandfonline.com/doi/full/ 10.1080/09687599.2017.1331838?cas a_token=PD7yznuFOVIAAAAA:2ty cO4jOinBGEHePepG4_PCcJGdmov 7aSbJ231 yiP5quYCm2bmABOOJdd 1G0HVaU1R5 8xKrrrLf

Webb, C. A., Beard, C., Kertz, S. J., Hsu, K. J., \& Björgvinsson, T. (2016). Differential role of CBT skills, DBT skills and cognitive flexibility in predicting depressive versus anxiety symptom improvement. Behaviour research and therapy, 81, 12-20. Available at:

https://www.ncbi.nlm.nih.gov/pmc/ar ticles/PMC4860036/

Wood, A., \& Burchell, B. (2018). Unemployment and Well-Being. The Cambridge Handbook of Psychology and Economic Behaviour. Edited by Lewis Alan, 234-258.

Zmigrod, L., Rentfrow, P. J., Zmigrod, S., \& Robbins, T. W. (2018). Cognitive flexibility and religious disbelief. Psychological Research, 83, 17491759. 


\section{Appendix A}

Principal components of the Unemployment Anxiety Scale

\begin{tabular}{|c|c|c|c|}
\hline & RC1 & RC2 & RC3 \\
\hline I feel that qualifying individuals with disabilities for the job market is poor. & -0.18 & 0.54 & 0.02 \\
\hline $\begin{array}{l}\text { I expect employers to have less confidence in the capabilities of individuals with } \\
\text { disabilities. }\end{array}$ & -0.34 & 0.85 & 0.11 \\
\hline I feel shy and not self-confident. & 0.55 & 0.41 & -0.44 \\
\hline $\begin{array}{l}\text { I am concerned about employers' view on individuals with disabilities possession of } \\
\text { professional skills. }\end{array}$ & 0.18 & 0.63 & -0.02 \\
\hline $\begin{array}{l}\text { It disturbs me that there are no training opportunities ending with employment for people } \\
\text { with disabilities. }\end{array}$ & -0.84 & 0.06 & 0.23 \\
\hline $\begin{array}{l}\text { I am concerned about the limitations of jobs available to individuals with disabilities in } \\
\text { very limited domains. }\end{array}$ & -0.87 & 0.03 & 0.16 \\
\hline $\begin{array}{l}\text { I feel concerned that there are no occupations appropriate for the capabilities of individuals } \\
\text { with disabilities. }\end{array}$ & -0.82 & 0.20 & 0.08 \\
\hline I think that I will fail even if I secured a job opportunity. & 0.90 & -0.13 & 0.02 \\
\hline I feel that I will not be able to complete the tasks required for work. & 0.54 & 0.40 & 0.08 \\
\hline I am concerned about employers' unawareness on how to deal with people with disabilities. & -0.43 & 0.22 & -0.32 \\
\hline I fear failure in job interviews. & 0.04 & 0.74 & -0.07 \\
\hline $\begin{array}{l}\text { I am afraid of unemployment due to my family's fear and lack of confidence in my } \\
\text { abilities. }\end{array}$ & 0.11 & 0.12 & 0.36 \\
\hline I am afraid that I will not be able to secure a job after graduating. & -0.21 & 0.44 & 0.54 \\
\hline I think that circumstances will be difficult after graduation. & 0.04 & 0.70 & 0.18 \\
\hline I expect to face difficulty in finding a suitable job. & -0.19 & 0.88 & 0.04 \\
\hline I fear to be a burden on my family after graduating. & -0.23 & 0.06 & 0.35 \\
\hline I fear not finding a suitable job related to my specialization. & -0.20 & -0.27 & 0.77 \\
\hline I feel anxious to compete for a job. & -0.20 & 0.12 & 0.78 \\
\hline I expect the worst after graduating. & 0.31 & 0.19 & 0.67 \\
\hline I feel that my university study is useless. & 0.49 & 0.07 & 0.59 \\
\hline I expect that I will be compelled to work in a job not relevant to my specialization. & 0.18 & -0.02 & 0.55 \\
\hline I feel that my potential is lower than what is required in working conditions. & 0.74 & -0.08 & 0.32 \\
\hline I feel much physical troubles whenever I remember my mysterious future career. & 0.64 & -0.10 & 0.29 \\
\hline I worry whenever I imagine the scene of job interviews. & 0.29 & 0.40 & -0.20 \\
\hline
\end{tabular}

Rotation Method is Promax..

\section{Appendix B}

\section{Principal components of the Ryff Psychological Wellbeing Scale}

\begin{tabular}{|c|c|c|c|c|c|c|c|}
\hline & RC1 & RC5 & RC6 & $\mathrm{RC3}$ & RC2 & RC4 & RC7 \\
\hline $\begin{array}{l}\text { I am not afraid to voice my opinions, even when } \\
\text { they are in opposition to the opinions of most } \\
\text { people. }\end{array}$ & 0.66 & 0.09 & 0.14 & 0.05 & $\begin{array}{c}- \\
0.21\end{array}$ & $\begin{array}{c}- \\
0.04\end{array}$ & 0.13 \\
\hline In general, I feel I am in charge of the situation in & 0.81 & 0.00 & - & 0.25 & 0.22 & - & -0.07 \\
\hline I am not interested in activities that will expand & 0.49 & - & - & 0.50 & 0.18 & - & -0.21 \\
\hline
\end{tabular}




\begin{tabular}{|c|c|c|c|c|c|c|c|}
\hline & RC1 & RC5 & RC6 & RC3 & $\mathrm{RC2}$ & $\mathrm{RC4}$ & RC7 \\
\hline \multirow{5}{*}{$\begin{array}{l}\text { my horizons. } \\
\text { Most people see me as loving and affectionate. } \\
\text { I live life one day at a time and don't really think } \\
\text { about the future. } \\
\text { When I look at the story of my life, I am pleased } \\
\text { with how things have turned out. }\end{array}$} & & 0.04 & 0.03 & & & 0.02 & \\
\hline & 0.65 & 0.14 & . & 0.26 & 0.00 & 0.00 & -0.03 \\
\hline & & & & & & & \\
\hline & 0.21 & 0.04 & 0.27 & 32 & 0.03 & 0.08 & -0.04 \\
\hline & 0.17 & 0.31 & 0.37 & 0.31 & 0.09 & 0.06 & $\mathbf{0 . 3 3}$ \\
\hline $\begin{array}{l}\text { My decisions are not usually influenced by what } \\
\text { everyone else is doing. }\end{array}$ & 1.02 & $\overline{0.32}$ & 0.14 & 0.09 & 0.06 & 0.17 & -0.18 \\
\hline The demands of everyday life often get me down. & 0.10 & 0.09 & - & .22 & - & - & -0.01 \\
\hline $\begin{array}{l}\text { I think it is important to have new experiences } \\
\text { that challenge how you think about yourself and } \\
\text { the world. }\end{array}$ & $\overline{0}$ & 0.14 & $0 . \overline{0}$ & $0 . \overline{16}$ & 0.23 & 0.07 & -0.12 \\
\hline $\begin{array}{l}\text { Maintaining close relationships has been difficult } \\
\text { and frustrating for me. }\end{array}$ & 0.10 & 0.20 & 0.05 & 0.34 & 0.58 & 0.12 & -0.24 \\
\hline direction and purpose in life. & - & 0.07 & - & - & - & - & -0.04 \\
\hline $\begin{array}{l}\text { In general, I feel confident and positive about } \\
\text { myself. }\end{array}$ & 0.60 & 0.56 & 0.11 & - & - & 0.06 & -0.23 \\
\hline o worry about what other people think of & 0.38 & - & 0.04 & - & 0.19 & - & 0.10 \\
\hline $\begin{array}{l}\text { ell with the people and the } \\
\text { d me. }\end{array}$ & 0.14 & 0.21 & 0.37 & & $\overline{0.34}$ & 0.09 & -0.24 \\
\hline $\begin{array}{l}\text { I haven't really improved } \\
\text { the years. }\end{array}$ & $\overline{-}-$ & $-\overline{1}$ & 0.70 & 0.25 & & 0.07 & 0.11 \\
\hline $\begin{array}{l}\text { I ofte } \\
\text { frien }\end{array}$ & 0.16 & 0.18 & 0.06 & & 0.02 & 0.06 & 0.09 \\
\hline often seem trivial and & 0.13 & $\begin{array}{c}- \\
0.11\end{array}$ & 0.79 & 0.07 & $\overline{-}-$ & 0.16 & 0.18 \\
\hline $\begin{array}{l}\text { I feel li } \\
\text { more o }\end{array}$ & 0.07 & 0.10 & 0.82 & 0.07 & 0.24 & 0.08 & -0.09 \\
\hline $\begin{array}{l}\text { I tend to be influenced by people with strong } \\
\text { opinions. }\end{array}$ & 0.56 & 0.07 & $\begin{array}{c}- \\
0.10\end{array}$ & 0.25 & $0 . \overline{2} 1$ & 0.22 & 0.02 \\
\hline $\begin{array}{l}\text { I am q } \\
\text { respon }\end{array}$ & 0.39 & 0.44 & $-\overline{13}$ & 0.05 & 0.25 & $0 . \overline{0}$ & 0.23 \\
\hline $\begin{array}{l}\text { e that I have developed a lot as a } \\
\text { ee. }\end{array}$ & 0.80 & 0.05 & 0.32 & $\overline{-} \cdot$ & 0.12 & $\begin{array}{c}- \\
0.01\end{array}$ & 0.08 \\
\hline $\begin{array}{l}\text { and mutual conversations with } \\
\text { or friends. }\end{array}$ & 0.42 & 0.48 & 0.12 & $\overline{-}-$ & 0.22 & $0 . \overline{20}$ & 0.25 \\
\hline sense of what it is I'm & 0.34 & 0.25 & 0.27 & 0.31 & $\begin{array}{c}0.00 \\
-\end{array}$ & 0.35 & 0.09 \\
\hline $\begin{array}{l}\text { I like } \mathrm{m} \\
\text { I have c }\end{array}$ & 0.81 & $\begin{array}{c}0.01 \\
-\end{array}$ & 0.04 & 0.04 & 0.07 & 0.06 & 0.02 \\
\hline & $\begin{array}{c}0.99 \\
-\end{array}$ & $\begin{array}{c}- \\
0.15 \\
-\end{array}$ & 0.06 & $\begin{array}{c}0.00 \\
-\end{array}$ & 0.00 & $0 . \overline{11}$ & 0.15 \\
\hline $\begin{array}{l}\text { I often feel overwhelmed by my responsibilities. } \\
\text { I do not enjoy being in new situations that require } \\
\text { me to change my old familiar ways of doing }\end{array}$ & 0.08 & 0.05 & 0.11 & 0.01 & 0.84 & 0.28 & -0.09 \\
\hline & 0.29 & 0.43 & 0.00 & 0.28 & $\mathbf{0 . 3 3}$ & $\mathbf{0 . 4 3}$ & -0.07 \\
\hline $\begin{array}{l}\text { People would describe me as a giving person, } \\
\text { willing to share my time with others. }\end{array}$ & 0.20 & 0.75 & $0 . \overline{21}$ & - & 0.13 & 0.06 & 0.16 \\
\hline $\begin{array}{l}\text { I enjoy making plans for the future and working to } \\
\text { make them a reality. }\end{array}$ & 0.44 & 0.18 & $\overline{-}$ & $\overline{-} \cdot$ & $\overline{-} \cdot$ & $\mathbf{0 . 5 5}$ & 0.10 \\
\hline
\end{tabular}




\begin{tabular}{|c|c|c|c|c|c|c|c|}
\hline & RC1 & RC5 & RC6 & RC3 & RC2 & RC4 & RC7 \\
\hline In many ways, I feel disappointed about my & - & (17 & 011 & (2) & 010 & 077 & 000 \\
\hline $\begin{array}{l}\text { achievements in life. } \\
\text { It's difficult for me to voice my own opinions on }\end{array}$ & 0.22 & $\begin{array}{c}0.11 \\
-\end{array}$ & 0.14 & $\begin{array}{c}0.21 \\
-\end{array}$ & 0.10 & $\begin{array}{c}0.77 \\
-\end{array}$ & \\
\hline 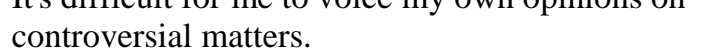 & 0.03 & 0.15 & 0.47 & 0.04 & 0.72 & 0.14 & -0.23 \\
\hline I have difficulty arranging my life in a way that is & 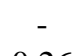 & & & & & & \\
\hline satisfying to me. & 0.26 & 0.05 & 0.08 & 0.19 & 0.71 & 0.22 & 0.27 \\
\hline $\begin{array}{l}\text { For me, life has been a continuous process of } \\
\text { learning, changing, and growth. }\end{array}$ & 0.10 & 0.20 & 0.12 & 0.05 & 0.20 & 0.05 & 0.74 \\
\hline I have not experienced many warm and trusting & - & & & & & - & \\
\hline relationships with others. & 0.10 & 0.02 & 0.28 & 0.40 & 0.18 & 0.23 & 0.53 \\
\hline $\begin{array}{l}\text { Some people wander aimlessly through life, but I } \\
\text { am not one of them }\end{array}$ & 0.27 & 0.59 & 0. & 0. & 0.04 & 0.32 & -0.04 \\
\hline My attitude about myself is probably not as & & & & - & & - & \\
\hline positive as most people feel about themselves. & 0.02 & 0.22 & 0.66 & 0.08 & 0.14 & 0.19 & -0.03 \\
\hline I judge myself by what I think is important, not by & & - & - & - & - & & \\
\hline $\begin{array}{l}\text { the values of what others think is important } \\
\text { I have been able to build a home and a lifestyle }\end{array}$ & 0.01 & $\begin{array}{c}0.17 \\
-\end{array}$ & 0.03 & 0.05 & 0.08 & 0.31 & 0.91 \\
\hline for myself that is much to my liking. & 0.81 & 0.08 & 0.21 & 0.30 & 0.01 & 0.17 & -0.18 \\
\hline $\begin{array}{l}\text { I gave up trying to make big improvements or } \\
\text { changes in my life a long time ago. }\end{array}$ & $\overline{0.03}$ & - & - & 0.14 & 0.07 & 0.81 & 0.47 \\
\hline I know that I can trust my friends, and they know & - & & - & - & - & - & \\
\hline they can trust me. & 0.16 & 0.06 & 0.06 & 0.61 & 0.29 & 0.04 & -0.13 \\
\hline $\begin{array}{l}\text { I sometimes feel as if I've done all there is to do in } \\
\text { life. }\end{array}$ & 0.03 & 0.02 & 0.27 & 0.49 & 0.07 & 0.16 & -0.02 \\
\hline $\begin{array}{l}\text { When I compare myself to friends and } \\
\text { acquaintances, it makes me feel good about who I } \\
\text { am. }\end{array}$ & 0.73 & 0.00 & 0.13 & 0.09 & 0.02 & $\begin{array}{c}- \\
0.04\end{array}$ & 0.15 \\
\hline
\end{tabular}

Rotation Method is Promax

\section{Appendix C}

\section{The second-order factor of psychological wellbeing}

\begin{tabular}{ll}
\hline & PC1 \\
\hline RC1 & $\mathbf{0 . 7 7}$ \\
RC5 & $\mathbf{0 . 7 2}$ \\
RC6 & $\mathbf{0 . 7 4}$ \\
RC3 & $\mathbf{0 . 5 5}$ \\
RC2 & $\mathbf{0 . 5 1}$ \\
RC4 & $\mathbf{0 . 5 4}$ \\
RC7 & $\mathbf{0 . 4 6}$ \\
\hline
\end{tabular}




\section{Appendix D}

\section{Principal components of the Cognitive Flexibility Questionnaire}

\begin{tabular}{|c|c|c|c|}
\hline & RC1 & RC2 & RC3 \\
\hline I am good at "sizing up" situations. & -0.52 & 0.34 & -0.01 \\
\hline I have a hard time making decisions when faced with difficult situations. & 0.70 & 0.03 & 0.13 \\
\hline I consider multiple options before making a decision. & -0.41 & 0.53 & -0.02 \\
\hline When I encounter difficult situations, I feel like I am losing control & 0.86 & 0.28 & 0.13 \\
\hline I like to look at difficult situations from many different angles. & -0.64 & 0.45 & 0.18 \\
\hline $\begin{array}{l}\text { I seek additional information not immediately available before attributing } \\
\text { causes to behavior. }\end{array}$ & -0.62 & 0.40 & 0.17 \\
\hline $\begin{array}{l}\text { When encountering difficult situations, I become so stressed that I cannot } \\
\text { think of a way to resolve the situation. }\end{array}$ & 0.78 & -0.01 & 0.09 \\
\hline $\begin{array}{l}\text { I try to think about things from another person's point of view. } \\
\text { I find it troublesome that there are so many different ways to deal with }\end{array}$ & -0.89 & -0.03 & 0.19 \\
\hline difficult situations. & 0.82 & 0.15 & 0.02 \\
\hline I am good at putting myself in others' shoes. & 0.02 & 0.63 & -0.19 \\
\hline When I encounter difficult situations, I just don't know what to do. & 0.82 & 0.19 & 0.13 \\
\hline $\begin{array}{l}\text { It is important to look at difficult situations from many angles. } \\
\text { When in difficult situations, I consider multiple options before deciding }\end{array}$ & -0.49 & 0.40 & -0.05 \\
\hline how to behave. & -0.24 & 0.60 & -0.07 \\
\hline I often look at a situation from different viewpoints... & 0.17 & 0.83 & 0.09 \\
\hline I am capable of overcoming the difficulties in life that I face. & 0.25 & 0.88 & 0.11 \\
\hline $\begin{array}{l}\text { I consider all the available facts and information when attributing causes to } \\
\text { behavior. }\end{array}$ & 0.21 & 0.73 & -0.48 \\
\hline $\begin{array}{l}\text { I feel I have no power to change things in difficult situations. } \\
\text { When I encounter difficult situations. I stop and try to think of several wavs }\end{array}$ & 0.03 & 0.16 & 0.88 \\
\hline $\begin{array}{l}\text { to resolve it. } \\
\text { I can think of more than one way to resolve a difficult situation I'm }\end{array}$ & -0.46 & 0.53 & 0.09 \\
\hline confronted with. & -0.14 & 0.26 & -0.55 \\
\hline I consider multiple options before responding to difficult situations. & -0.05 & -0.15 & 0.75 \\
\hline
\end{tabular}

Rotation Method is Promax .

\section{Appendix E}

The second-order components of cognitive flexibility

\begin{tabular}{lc}
\hline & PC1 \\
\hline RC1 & $\mathbf{0 . 8 2}$ \\
RC2 & $\mathbf{- 0 . 8 0}$ \\
RC3 & $\mathbf{0 . 7 1}$ \\
\hline
\end{tabular}




\section{المرونة العقلية كمتغير وسيط في العلاقة بين قلق البطالة والرفاهية النفسية لاى عينة من طلاب الجامعة ذوي الإعاقة}

\author{
مجده السيد علي الكثكي \\ أستاذ علم النفس الاكلينيكي \\ قسم علم النفس - كلية الآد/ب والعلوم الانسانية \\ جامعتي الملك عبد العزيز بجده وأسبيوط ببصر
}

شادن خليل حسين عليوات 1

$$
\begin{aligned}
& \text { أستاذ مشارك } \\
& \text { قسم التربية الخاصة - كلية الدراسات العليا } \\
& \text { التربوية - جامعتة الملك عبد العزيز }
\end{aligned}
$$

مستخلص. تؤكد العديد من الدراسات السابقة أن الأفراد القلقين عادة ما يكون لديهم درجات منخفضة من الرفاهية

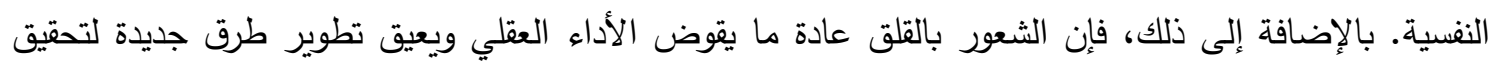

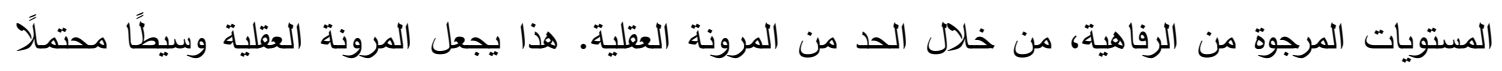
للعلاقة السلبية بين القلق والرفاهية. تهذف هذه الدراسة إلي التحقق مما إذا كانت المرونة العقلية بمثابة وسيط بين القلق والرفاهية النفسية، مع التركيز بشكل خاص على القلق من البطالة الذي يعاني منه الأفراد ذوو الإعاقة.

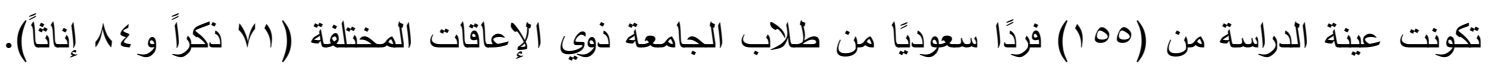

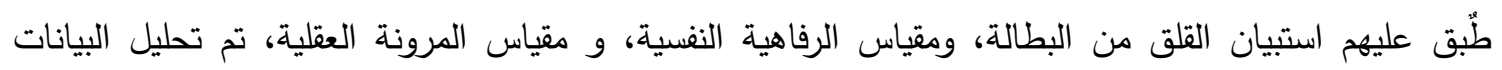
باستخدام برنامج R ، وأجري تحليل المسار • أظهرت نتائج تحليل المسار أن المرونة العقلية تعمل كوسيط جزئي بين القلق من البطالة والرفاهية النفسية. في ضوء النتائج أوصت الدراسة بتكرار الدراسة باستخدام تدابير أكثر تكيفًا وثقافيًا للتعرف على الاختلافات الثقافية المحتملة. الكلمات المفتاحية: قلق البطالة ، المرونة العقلية ، الرفاهية النفسية ، الإعاقة. 